\title{
NAS TENSÕES DE UM NOVO PAÍS: O ESPORTE EM CABO VERDE (1974- | 977)'
}

\author{
DR. VICTOR ANDRADE DE MELO \\ Faculdade de Educação, Universidade Federal do Rio de Janeiro \\ (Rio de Janeiro - Rio de Janeiro - Brasil) \\ E-mail: victor.a.melo@uol.com.br
}

\begin{abstract}
RESUMO
Esse artigo tem por objetivo discutir os posicionamentos sobre o esporte veiculados em quatro periódicos cabo-verdianos (Alerta!, Novo Jornal de Cabo Verde, Voz Di Povo e Terra Nova) nos anos iniciais do país independente (1974- 1977). Argumentamos que esse esforço permite-nos compreender o papel ocupado pela prática nos primeiros momentos da construção da ideia de nação em Cabo Verde, um caso relevante em função do caráter tardio desse processo e da peculiaridade da formação identitária no arquipélago. Ao fim conclui-se que os debates que envolveram o esporte, inclusive no que se refere à natureza das intervenções governamentais, expressavam em boa medida as tensões políticas, sociais e culturais do país naquele momento.
\end{abstract}

PALAVRAS-CHAVE: História do esporte; identidade; Cabo Verde; política.

I. Esse trabalho recebeu auxílio financeiro do Conselho Nacional de Desenvolvimento Científico e Tecnológico (Edital 18/2007/CPLP/CNPq, Edital 13/2008/CPLP/CNPq, Bolsa de Produtividade em Pesquisa) e da Fundação Carlos Chagas Filho de Amparo à Pesquisa do Estado do Rio de Janeiro (Edital Apoio a Grupos Emergentes/2008 e Edital Jovem Cientista do Nosso Estado/2008). 
O palco foi um campo de futebol. O motivo principal para tal escolha foi de natureza operacional: acolher o maior número de pessoas. De qualquer forma, não deixa de ser simbólico o fato de que justamente o Estádio da Várzea, na cidade de Praia (Ilha de Santiago), a capital, tenha abrigado, no dia 5 de julho de 1975, a cerimônia de proclamação da independência de Cabo Verde: "logo as suas bancadas se mostraram insuficientes para a quantidade de gente, vinda dos mais diversos lugares do arquipélago e do estrangeiro" (LOPES, 2002, p. 22). ${ }^{2}$ Evento semelhante foi organizado no Estádio da Fontinha, em Mindelo (Illha de São Vicente). O esporte, mesmo que nesse caso ocasionalmente, uma vez mais fazia parte de um momentochave da história cabo-verdiana. ${ }^{3}$

Quem de forma desavisada mergulhou naquele clima de festa não podia ter uma ideia mais profunda das tensões que precederam aquele momento. Os grupos eram muitos, os embates foram múltiplos: militantes do Partido Africano pela Independência da Guiné e de Cabo Verde (PAIGC), que participaram dos conflitos armados na Guiné-Bissau e voltavam ao arquipélago, reivindicando o reconhecimento de seu protagonismo; os que eram ligados ao partido e tinham ficado na clandestinidade nas ilhas; os vinculados à causa que moravam em outros países, especialmente Portugal e Estados Unidos; os que tinham ação política, mas discordavam do partido revolucionário, entre os quais alguns que manifestaram dúvidas acerca da independência, perguntando-se se não era melhor reivindicar a manutenção da relação com a antiga metrópole, ainda que com autonomia administrativa, como ocorreu com os Açores e com a Madeira. ${ }^{4}$

Para complicar, Amílcar Cabral, um dos principais líderes das lutas pela independência, estava morto. Adenda-se a isso a instabilidade de Portugal, no momento pós-Revolução dos Cravos, marcado por tensões entre os diferentes grupos de poder e projetos para um país que saia de quase 50 anos de ditadura. Mais um problema não desprezível: os cofres da futura nação estavam vazios e a antiga metrópole não podia ajudar muito, também imersa em problemas financeiros que se agravavam com sua precária situação política. Ao fim, por motivos diversos, o PAIGC assumira o comando, adotando um regime de partido único, nos moldes dos países socialistas, embora oficialmente não alinhado. ${ }^{5}$

2. Umbrevefilme sobrea cerimônia de independência pode servisto em $<$ http://wnww.youtube.com/watch?v=pCuLF458 gs\&feature $=$ PlayList\& $=4$ | BC408BB050257A\&playnext_from $=$ PL\&playnext $=\mid$ \&index $=\mid 7>$. Acessado em: $\mid \overline{3}$ de maio de 2011 .

3. Como demonstra Melo (20 I0), desde o século XIX o esporte ocupa espaço de relevância na história de Cabo Verde.

4. Há, obviamente, várias interpretações sobre essas tensões. Algumas dessas posições podem ser encontradas nos livros de Querido (1988), Lopes (2002) e Pereira (2003).

5. lliffe (1999) demonstra que a adoção de partidos únicos foi uma ocorrência comum no cenário africano pósindependências: "Quando o Muro de Berlim caiu em 1989, apenas sete dos quarenta e cinco estados subsaarianos eram adeptos do pluralismo político" (p. 338). 
A compreensão do que deveria ser a nação, a partir de então, apontaria para algo bastante distinto do que fora majoritário no arquipélago desde o século $\mathrm{XIX}$, inclusive por um controvertido projeto de construção de um Estado em comum com a Guiné-Bissau. Substituindo uma exaltada ideia de identidade mestiça, a representação de que o cabo-verdiano aprendeu a aproveitar o melhor dos dois mundos que o formam (África e Europa) sem ser exatamente nenhum dos dois, ${ }^{6}$ a opção pela "africanidade" seria explicitada nos discursos, em algumas ações e nos símbolos oficiais - a bandeira e o hino nacionais eram expressão desse novo momento. Fernandes (2006) se pergunta se:

nessas condições e moldes o projeto nacionalista africano não encerraria em si a preterição ou até negação da nação cabo-verdiana, fosse ela preexistente e latente, baseada na peculiaridade sociocultural cabo-verdiana, ou virtual, baseada num sentimento subjetivo, voltado para o futuro (p. 20I).

Considerando esse quadro, esse artigo tem por objetivo discutir os posicionamentos e debates sobre o esporte veiculados nos jornais cabo-verdianos no período que vai de 1974, início do processo de transição para a independência, até 1977, momento de uma primeira mudança nos rumos das ações governamentais. Foram analisados: o Alerta!, lançado em 1974, que teve pouca duração; o Novo Jornal de Cabo Verde, editado entre agosto de 1974 e julho de 1975; o Voz Di Povo, publicado sob responsabilidade do partido único do país já independente (PAIGC); e o Terra Nova, dirigido pela igreja católica.

Obviamente, haveria outras fontes possíveis para abordar o período. Todavia, dada a importância da imprensa na história de Cabo Verde, expressão de uma sociedade civil que se organizava desde o século XIX, argumentamos que o debate nela veiculado nos permite captar algo sobre o papel ocupado pelo esporte nos primeiros instantes da construção da ideia de nação ${ }^{7}$ no jovem país, um caso relevante pelo caráter tardio desse processo e pela peculiaridade da formação identitária cabo-verdiana.

\section{NÃO MAIS AQUELE DESPORTO}

Comecemos pelo Alerta!, periódico que teve vida curta até mesmo por se assumir como "anticolonialista, antifascista, antiburguês, revolucionário, pró-africano e pelo PAIGC" (OLIVEIRA, I998, p. 593) em um momento em que se fazia

6. Para mais informações, ver Fernandes (2006).

7. Para definir a ideia de construção da nação a partir de elementos discursivos simbólicos e materiais, trabalhamos com Benedict Anderson (1991). 
necessário, pelo menos nos discursos, um pouco mais de equilíbrio em função da situação de transição. ${ }^{8}$

Desde o primeiro número, notícias sobre o esporte foram publicadas nesse jornal. Na seção "Noticiário de Cabo Verde" encontramos informações sobre uma ocorrência comum na história do futebol cabo-verdiano, algo que sempre incomodou as lideranças intelectuais no período colonial e seguirá incomodando os partidários do regime que está para começar: "Lamentáveis incidentes assinalaram a tarde desportiva do domingo, no Estádio da Várzea. Devido a ameaças de agressão ao árbitro, feitas por jogadores, o desafio Acadêmica-Boavista não passou dos trinta minutos na primeira parte".

Fato semelhante se passou em um jogo entre o Sporting e os Travadores: um grupo de descontentes tentou agredir o árbitro, que se escondeu, com a ajuda da polícia, no carro de um particular. O confronto, contudo, não cessou: o veículo e os policiais foram atingidos por pedras e garrafas. Os agentes reagiram, atirando para o alto, e acabaram acertando em alguém. Os envolvidos transformaram o fato em uma manifestação política, que caminhou rumo ao Palácio do Governo com o ferido nas mãos.

Em Mindelo houve confrontos semelhantes, o que levou cerca de três mil pessoas, "representando as forças políticas mais representativas de São Vicente", a se encontrarem no Grêmio Desportivo Castilho, "aprovando uma moção, na qual condenaram a provocação, seguida de violência, contra a população, por parte da PSPI0".

Em relação ao passado, o que difere nesses casos é o grau exacerbado tanto do conflito quanto da forma que foi noticiado, bem como do desfecho dos tumultos, algo que parece mesmo ter relação com o momento tenso pelo qual passava o arquipélago, ânimos acirrados que induziam a confrontos com as autoridades.

Os conflitos em Praia mereceram ainda mais destaque na coluna dedicada aos esportes. Na matéria "Balanço geral - Jogo - Hostilidade, expulsões, agressões, polícias, tiros, ferimentos, tudo isto atentando contra o Desporto", A. Correia e Silva afirma:

Não é novidade afirmar que o desporto entre nós está em crise: sempre esteve. Crise de valores. De jogadores. De árbitros. De dirigentes. As poucas exceções não contam. A "futebolite" é epidêmica. Tudo doente. Mas, sobretudo, crise de estrutura. Pior que os doentes é a doença. ${ }^{11}$

8. O editor, David Almada, assim apresentou o periódico no primeiro número (ano I, número I, 27 de junho de 1974): "O Alerta! será sempre o veículo de consciencialização, mentalização e politização de um povo a quem, durante mais de quinhentos anos, não se ensinou sequer pronunciar essas palavras. Será a voz da revolta, será a voz da verdade, será a voz da solução, será a voz da vitória" (p. I).

9. Alerta!, ano I, número I, 27 de junho de 1974, p. 3.

10. Polícia de Segurança Pública. Alerta!, ano I, número I, 27 de junho de 1974, p. 4.

II. Alerta!, ano I, número I, 27 de junho de 1974, p.9. 
Para o colunista, tais problemas estavam relacionados ao colonialismo, que deveria ser superado definitivamente, uma clara vinculação à ideia de que a independência era a melhor opção para Cabo Verde: "O que se passa no âmbito desportivo é o que também acontece noutros aspectos da vida social, ou dito inversamente. Para evitar doentes, só eliminando a doença" (p. 9).

O tema, com outro enfoque, voltará a ser debatido na coluna de esporte do segundo número de Alerta!. Ao comentar a final de um campeonato de futebol realizado em Praia, afirma o jornalista:

\begin{abstract}
Há alguns anos (...) que a final do Campeonato de Cabo Verde nos vem oferecendo um espetáculo horroroso, manchando não só a ética desportiva como também alimentando o forte bairrismo que opõe a maior parte dos naturais desta ilha à igual facção do "desportorei" de São Vicente. ${ }^{12}$
\end{abstract}

Para ele, isso tem relação não só com o quadro político nacional, mas também com a "ação maléfica" dos meios de comunicação, que contribuíam para a degradação do esporte. Supõe que não será possível fazer grandes alterações para a próxima final, mas reivindica que sejam pensadas mudanças urgentes, tendo em vista que: "A tentativa de união de todos os cabo-verdianos nunca foi tão necessitada como agora, devendo ela impor-se acima de quaisquer reivindicações que não dizem respeito à maior parte da população" (p. 7).

Nessa edição é ainda publicado o texto "Desporto - parte integral da Educação", assinado por Félix Gomes Monteiro, dividido em "Do direito de todos a praticar o desporto", "Das obrigações do desportista", "Dos deveres dos técnicos desportivos", "Dos deveres dos dirigentes desportivos". Trata-se de uma primeira tentativa de anúncio em meio ao grande número de denúncias que marcou o início do período de transição.

Nós números seguintes do jornal seguiram sendo publicadas críticas e apreensões com os problemas com o futebol. A última edição anuncia algo mais das tensões que terão que ser enfrentadas pelo governo que em breve vai se constituir. Orlando Mascarenhas comenta a péssima qualidade técnica do jogo decisivo da competição da capital: "Foi uma modestíssima final (...) como aliás modestíssimo é tudo quanto se relaciona com esta nossa pobre terra. Uma final com todo o seu amadorismo, todas as suas falhas, toda a sua pobreza, todo o seu primitivismo, em fim, um futebol voltado ao esquecimento". ${ }^{13}$

Os desafios eram muitos, como tudo o que cerca um país que está para nascer. Esboçava-se de forma bem pouca precisa uma nova visão de esporte,

12. Ano I, número 2, 4 de julho de 1974, p. 7.

13. Ano I, número 5,25 de julho de 1974, p. II. 
supostamente mais adequada aos princípios do que deveria ser um novo tempo. Não se tinha muita noção do que deveria ser esse novo olhar. De qualquer maneira, ainda que discretamente, já se elegia o inimigo: o colonialismo.

\section{QUE DESPORTO?}

O Novo Jornal de Cabo Verde majoritariamente expõe os debates sobre o futuro do país, sendo claramente perceptíveis as tensões entre os diversos grupos políticos locais. Até mesmo por esse quadro, com tantas questões a serem tratadas, o esporte demora a aparecer em suas folhas. Somente no número 8 , de 19 de setembro de 1974, vemos uma breve notícia sobre um jogo entre os Travadores e o Sporting, vencido pelo primeiro.

No número 13, de 24 de outubro de 1974, publica-se uma reportagem sobre a organização dos Jogos Olímpicos de 1980, a serem realizados em Moscou. Demonstra-se simpatia pelo governo soviético, mas nada que denuncie claramente uma relação que futuramente seria estabelecida. Na verdade, o que ocorre é que as discussões sobre o socialismo na ainda metrópole ecoavam diretamente nos debates locais.

Não surpreende, assim, que no número 23, de 16 de janeiro de 1975, tenha sido publicado um extrato de um jornal português (não informado) cujo título era "Para um esporte democrático". Devemos ter em conta que em Portugal, onde se discutia o futuro a partir da crítica ao longo período de ditadura Salazar/Caetano, também se estava a repensar o papel da prática esportiva no novo país que se esperava construir.

A primeira posição mais categórica sobre o esporte publicada no Novo Jornal de Cabo Verde pode ser observada no número 22, de 9 de janeiro de 1975, um artigo de Jorge Pereira, intitulado "Que desporto...". Segundo o autor, "Antes propriamente de fornecer os meios necessários à prática de tal ou tal desporto, nesta ou naquela localidade, impõe-se um difícil trabalho de sensibilização e mentalização das pessoas em relação aos benefícios e necessidade de uma prática desportiva livre" (p. 7).

Uma vez mais é apontada a necessidade de que a prática esportiva estivesse sintonizada com os "novos tempos". Para tal, segundo o autor, o intuito de uma política de esporte deveria ser o de democratização e dinamização cultural, sustentada em três eixos: a escola, o local de trabalho, as associações civis e religiosas.

Tratava-se de um posicionamento ainda impreciso, o lançar de algumas noções que depois seriam referendadas nos discursos do partido único. Naquele momento da transição ainda percebia-se menos um tom propositivo e mais um caráter de conclamação: 
Que todos participem na elaboração, discussão e concretização de programas que, no domínio da educação física e desportiva, sejam criadas as condições mínimas permissivas de levar a prática de um desporto para todos por aqueles que sempre por ele pugnaram, por todos os que queiram e sejam capazes (p. 7).

Depois de uma série de breves notícias espalhadas por vários números, algo relevante relacionado à prática esportiva pode ser encontrado no número 32, de 20 de março de 1975. O Grêmio Amarante, de Mindelo, organizara um torneio de futebol para comemorar seu aniversário e solicitara a Aristides Pereira (secretário geral do PAIGC que logo se tornaria o primeiro presidente do país) autorização para homenageá-lo com o nome da taça. A resposta do dirigente, na forma de um telegrama, é indicadora de como o esporte passaria futuramente a ser tratado pelo governo:

Sinto-me honrado vossa proposta a qual aceito muito agrado convencido libertação nossa terra pressupõe necessariamente fundamentalmente nossa libertação cultural isso exige esforço crescente campo desportivo fim permitir sobretudo nossa juventude de realizar-se totalmente sã física espiritualmente nosso partido garante no seu programa trabalhar sentido criar condições necessárias indispensáveis nosso povo realizar uma política campo desporto totalmente aberta dignos filhos nossa terra sem discriminação valorizando melhor forma aqueles merecedores confiante futuro desportivo nosso país independente (p. 7).

Essa ação do Amarante destoa de uma linha de contraposição ao PAIGC que era muito forte em São Vicente: a Ilha foi a sede da União Democrática de Cabo Verde (UDC) e da União do Povo das Ilhas de Cabo Verde (UIPCV), grupos que contestavam até mesmo a independência como a opção mais adequada para o arquipélago. ${ }^{14}$ Nesse contexto, inclusive, o Grêmio Recreativo de Mindelo, uma das mais antigas agremiações, e a Rádio Barlavento foram as sedes das tensões, sendo a última mesmo invadida por partidários do PAIGC, em dezembro de 1974.

Humberto Santos (apud PEREIRA, 2003) apresenta um ponto de vista interessante sobre essa ocorrência. Para ele, havia uma representação de que o Grêmio Recreativo de Mindelo era "um bastião da presença colonial, na medida em que todos os tenores do regime tinham acesso" (p.45I). Ainda que reconheça que havia sócios envolvidos com os problemas de Cabo Verde, a invasão, para Santos, "teve um significado simbólico importante, por aquilo que ela representava como caixa de ressonância do establishment" (p. 45I). ${ }^{15}$

14. Para mais informações, ver Pereira (2003).

15. Esse episódio desencadeia polêmicas até os dias de hoje, não sendo poucos os que consideram a tomada da Rádio Barlavento um ato de violência injustificada. 
Voltemos ao Novo Jornal de Cabo Verde. É somente no número 39, de 15 de maio de 1975, que identificamos uma ação mais concreta do governo de transição: a criação de uma comissão para tratar das questões do esporte, formada por três portugueses, três representantes das ilhas de Sotavento e cinco representantes das ilhas de Barlavento, o que demonstra que, pelo menos simbolicamente, São Vicente continuava sobrepujando Santiago em prestígio no tema. Esse órgão deveria propor políticas, propostas e programas a partir de um inventário das ações, dos fundos e dos bens do antigo Conselho Provincial de Educação Física. ${ }^{16}$

Não houve muito tempo para esse novo órgão atuar: a independência estava próxima, os discursos seriam radicalizados, novos tempos estavam, pelo menos nas representações, para chegar.

\section{POR UM DESPORTO NOVO: A PRÁTICA ESPORTIVA E OS DISCURSOS SOBRE A NOVA NAÇÃO}

Com o fim do período de transição, extinguiu-se o Novo Jornal de Cabo Verde, substituído pelo Voz di Povo, lançado em 17 de julho de 1975, no mesmo dia em que tomava posse o primeiro governo do país independente.

Nos primeiros números do novo periódico, as matérias fazem uma apresentação de projetos para o país. Algumas notícias esparsas sobre o esporte são publicadas, mas é mesmo na edição de 21 de novembro de 1975 que o tema é abordado diretamente na matéria "Por um desporto novo". Já se percebe no discurso os novos pressupostos políticos em vigor:

Com efeito, o vedetismo, o sensacionalismo, o desporto comercializado, com venda e compra constante de jogadores, o atleta escravizado, são fatos que não podemos deixar de deplorar, dado que são a negação do desporto como atividade saudável, não só para o corpo, como para o espírito. ${ }^{17}$

Segundo o olhar do jornalista, havia um excesso de atenção para com o futebol, que no tempo colonial teria servido como forma de alienação e divisão do povo cabo-verdiano, uma chave usada para entender a má-organização e os constantes tumultos observados nas competições. Assim, afirma: "Não pretendemos minimizar o chamado 'desporto-rei', mas tão-só chamar a atenção dos nossos desportistas para outras modalidades" (p. 4).

16. Órgão ligado à Secretaria Provincial de Educação, instalado em cada uma das províncias portuguesas.

17. Voz di Povo, ano I, número 18, 21 de novembro de 1975, p. 4. 
A promessa era de que com a independência tudo mudaria. Os jogos deveriam ser encarados como forma de confraternização e união, "tanto da parte dos jogadores, como do público, finalmente conscientes de serem filhos da mesma terra e de se estar a viver uma situação totalmente nova" (p. 5).

A matéria apresenta ainda as visões de esporte da União Soviética e da Alemanha Oriental, já deixando claras as novas inspirações do país. Tornou-se constante com o decorrer do tempo a publicação de notícias dessa natureza, uma propaganda política explícita.

De fato, o relacionamento com os países do leste europeu foi muito comum no continente africano pós-independências. Baruch Hazan ( 1987) lembra que o investimento no esporte foi uma importante parte da política externa soviética, uma das ferramentas utilizadas para estimular a adoção do socialismo e conformar a sua hegemonia. A relação basicamente se estabelecia com o apoio às reivindicações de países da África nos organismos internacionais (notadamente no Comitê Olímpico), com a concessão de bolsas para atletas estudarem e treinarem na União Soviética e com o envio de auxílio financeiro, de material e de especialistas para as equipes nacionais. Enfim:

as relações do esporte soviético com a África serviram à finalidade de facilitar o desenvolvimento das relações em outras áreas, bem como demonstrar as vantagens do sistema político soviético. Essas conclusões parecem óbvias quando analisamos as declarações oficiais de africanos sobre a importância das relações esportivas com a URSS. Muitos deles sublinharam os aspectos políticos das relações e da sua utilidade em muitas áreas (HAZAN, 1987, p. 267).

Na verdade, no novo cenário político propugnou-se a noção de que o esporte deveria expressar e ajudar a forjar o "o novo homem cabo-verdiano". ${ }^{18}$ No número 20, de 5 de dezembro de 1975, vemos esse enfoque na notícia sobre a partida final do primeiro campeonato de futebol pós-independência, ocasião que contou com a presença do presidente Aristides Pereira e de todo o corpo ministerial. $\bigcirc$ evento foi celebrado como o renascimento do esporte em Cabo Verde, oportunidade para reafirmar os compromissos e desafios do novo regime no que se refere à prática: "O desporto, para que cumpra a função na sociedade nova, tem que se encaminhar pela via da desalienação, a fim de se consciencializar e melhor servir a sua massa de praticantes" (p. 7).

Em linhas gerais, a proposta do PAIGC era:

18. A ideia de forjar um novo homem foi comum em muitos países que adotaram o socialismo, e estava presente, com diferentes enfoques, no pensamento de importantes líderes como Stalin, Lenin, Mao Tse-tung, Che Guevara, Fanon, Paulo Freire e Amílcar Cabral. 
Massificação e diversificação das atividades desportivas, particularmente para as modalidades que durante a época colonial nunca se efetuaram ou foram praticadas de uma forma inconsequente, desintegradas do sistema educativo e caracterizadas por uma quase ausência de técnica. ${ }^{19}$

As críticas sempre tinham em conta estabelecer um contraponto com o período colonial:

Desempenhando um papel bastante educativo na evolução duma sociedade, o desporto exige, nessa fase de Reconstrução Nacional, uma atenção delicada. Foco donde provinham graves ameaças para a sociedade cabo-verdiana - divisionismo, alienação, etc., o desporto foi então inteligentemente utilizado pelo inimigo com a finalidade de fazer enfraquecer nossa unidade. Na nova sociedade que pretendemos construir o desporto terá que ser modelado de acordo com a nossa realidade, a fim de satisfazer os reais interesses da massa. ${ }^{20}$

Vejamos que essa visão de esporte estava presente até mesmo no Terra Nova. Produzido inicialmente na llha do Fogo e depois em São Vicente, tratava-se de um jornal religioso que também noticiava o cotidiano de Cabo Verde, por vezes se chocando com os ditames do PAIGC.

Por exemplo, João Cabral Rocha Furtado assim comenta as partidas de futebol realizadas por ocasião dos festejos da independência: "Quando soou o apito final do encontro os jogadores abraçaram-se, comovidos, por terem disputado um encontro onde todos demonstraram que, realmente, são capazes de praticar um desporto novo numa Terra Nova. (...) Viva o Desporto Novo!" (p. 5).

Enfim, as palavras de ordem do PAIGC pareciam efetivamente lograr, em maior ou menor grau, algum grau de penetrabilidade.

\section{TENSÕES}

A despeito de estar mais clara a proposta de esporte do novo governo, os desdobramentos não seguiram exatamente o que esperava o pensamento oficial. Da mesma forma que os envolvidos com a prática nunca aderiram linearmente ao que esperavam os representantes do poder no período colonial, também não o fizeram com o encaminhamento do partido único, até mesmo porque, do ponto de vista dos resultados, não houve grandes mudanças (nem seria possível em tão pouco tempo e no quadro conjuntural do arquipélago, que tinha mesmo problemas mais urgentes a resolver).

19. Voz di Povo, ano I, número 38, 19 de abril de 1976, p.8.

20. Voz di Povo, ano I, número 29, 26 de abril de 1976, p.2. 
Na edição do Voz di Povo de 18 de setembro de 1976, o jornalista não consegue conter a decepção, a despeito de ter tentado a todo custo argumentar o quão fora importante a participação de equipes de futebol de Cabo Verde em um quadrangular internacional:

Razão tínhamos nós quando (...) nos mostrávamos seriamente apreensivos em relação ao torneio quadrangular (...). Com efeito no final dos quatro jogos (...) vimos plenamente confirmados (...) o fraco nível técnico e tático das nossas equipes de futebol e o mal que pesa sobre essa modalidade em Cabo Verde. ${ }^{21}$

O tom de desculpa, mesmo que no sentido de reiterar as ideias governamentais sobre o esporte, fica também claro em matéria publicada na edição de 15 de janeiro de 1977:

Sendo Cabo Verde um país subdesenvolvido não é de esperar que ele (o desporto) tenha de imediato a craveira olímpica. Aliás, o desenvolvimento do desporto não deve, segundo cremos, ter por objetivo ir aos Jogos Olímpicos, antes visará as massas populares, não essencialmente mas sim como participação. ${ }^{22}$

Constantemente é possível perceber uma dubiedade: a crítica do "esporte capitalista", mas o desejo de obter bons resultados internacionais; a ideia de "servir ao povo", mas também de garantir uma maior projeção mundial. Isso fica explícito, por exemplo, quando o Voz di Povo celebra intensamente o $4^{\circ}$ lugar do cabo-verdiano José Correia na Corrida de São Silvestre de Angola. Afirma seu treinador, ao ser perguntado sobre o porquê de não um resultado melhor: "Há alguns vícios que um atleta tem de por de lado (tabaco e álcool inclusive) e já falei com o Zé acerca disso porque atualmente ele tem um papel a desempenhar servindo de exemplo aos mais jovens". ${ }^{23}$

Se para o partido único o esporte era uma ferramenta de formação e projeção internacional, para muitos dos envolvidos era uma ocasião de diversão: Zé Correia não via nenhum problema em fumar, beber, não treinar e correr. $\bigcirc$ problema é que isso feria não só a base moral, como também o desejo de melhores resultados dos dirigentes da jovem nação.

À visão ligada aos novos moldes de discurso político também agredia uma velha ocorrência: a todo tempo vemos em Voz di Povo que seguem os conflitos nos campos de futebol. No número 37, de 10 de abril de 1976, conclama-se: "Os jogadores precisam perder o feio hábito de falarem entre si e com o público e este

21. Voz di Povo, ano 2, número 59, p. 8.

22. Voz di Povo, ano 2, número 76, p. 6.

23. Voz di Povo, ano 2, número 74, I de janeiro de 1977, p. 8. 
deve deixar de dar instruções constantes aos jogadores em campo" (p. 8). Esses comportamentos eram considerados uma traição dos princípios da nova sociedade que se prospectava: "Um jogo de futebol pode dar origem a uma lição de ética, pode constituir uma aula de moral. Mas no domingo, no campo da Fontinha, essa imagem foi desvirtuada". ${ }^{24}$

Mais ainda, os históricos conflitos entre as duas mais importantes ilhas, São Vicente e Santiago, pareciam não só seguir como mesmo se acentuaram, provavelmente, inclusive, em função das novas orientações políticas, menos apoiadas pelos de Mindelo. $\bigcirc$ jornal por vezes até tentava minimizar tal ocorrência, celebrando supostas iniciativas de aproximação:

Prosseguindo na política de renovação do nosso desporto, a Acadêmica do Mindelo levou a efeito um torneio de futebol integrando equipes de Santiago, Sal e São Vicente (...). Iniciativa louvável e ao mesmo tempo arrojada, já que no primeiro caso as ilhas, antes afastadas, (...) agora passam a integrar o desporto nacional com toda sua força nacional. ${ }^{25}$

Na verdade, em meio a tantos problemas, o governo cobrava o que não dava, e isso acabou perceptível na observação de um jornalista em matéria publicada no Voz di Povo de número 74 (de I de janeiro de 1977), em que fazia um balanço do esporte em 1976 ("Dessa coisa chamada desporto a essa gente chamada desportista").

Já de início o jornalista dá indícios de que havia alguma forma de discriminação com o tema: "não minimize a página desportiva do jornal. E se o seu estatuto de estagiário para intelectual ou de intelectual já confirmado Ihe põe sérios problemas de ordens éticas, leia o 'desporto' disfarçadamente" (p.9). De fato, no novo quadro histórico, mudara a consideração para com a prática, por razões operacionais (dificuldades econômicas), mas também por motivos políticos (a ideia de que havia muita alienação ao seu redor, o que no arquipélago poderia até mesmo ser relacionado à força de Mindelo, centro das divergências).

Por fim, o jornalista tenta encontrar alguma justificativa para o quadro esportivo da época: "Claro que falamos aqui de desporto no seu sentido e dimensão universais que, por enquanto, em Cabo Verde, anda um pouco esquecido. Que é evidente, há tarefas mais prioritárias. Mas havemos de chegar lá. (...). Apreciemos o desporto que aqui e agora se pode ter e se pode viver" (p. 9).

Em outra ocasião, quando se faz um balanço da história do esporte em Cabo Verde, definitivamente se aceita o limitado quadro do desenvolvimento esportivo; conecta-se, contudo, o estágio da época com as deficiências do passado, algo que

24. Voz di Povo, ano I, número 38, 19 de abril de 1976, p. 8.

25. Voz di Povo, ano I, número 50, 17 de julho de 1976, p. 8. 
pode ter muito incomodado os mindelenses, com suas ideias de que fora glorioso o passado da prática esportiva na llha de São Vicente: "Longe de nos pretender dizer que somos um povo rico de tradições desportivas e que fomos exímios no passado. Nada disso, de uma forma ou de outra, andamos sempre a tatear". ${ }^{26}$

É importante observar que as críticas às posições e ações do PAIGC no âmbito esportivo ecoaram por anos, chegando até os dias atuais. Não surpreende que tenhamos encontrado um recente artigo de Casimiro de Pina, polêmico colunista local, sobre tal tema. O título, "A alucinante demagogia", ${ }^{27}$ já dá o tom de sua posição.

O autor critica o fato de que, segundo seu olhar, no período pós-independência o partido único tenha implementado uma política esportiva instrumental, orientada por preocupações ideológicas e por um caráter autoritário, simplesmente para servir aos interesses de controle do Estado:

\footnotetext{
O fio condutor dessa delirante "política desportiva" era, em síntese, a construção do "homem novo", objetivo perseguido com ardor e devoção "revolucionária". O desporto, prática humanamente significativa, não valia por si mesmo. Não era um direito individual, algo inerente ao caráter e à liberdade do praticante. $\bigcirc$ desporto não era uma escola de emulação e excelência. Era, tão somente, um instrumento do partido, um veículo da ideologia dominante e da "transformação social" pretendida.
}

Para Casimiro, sob inspiração soviética o esporte era apresentado como: "uma perene e inquebrantável corrente de unidade..., perspectivando aos atletas, dirigentes e clubes a grandeza duma nação, que se guinda ou se queda à medida das vitórias que consiga ou das derrotas que sofra, as quais, mesmo individuais, são sempre coletivas".

A crítica se dirige, portanto, à natureza da intervenção estatal no esporte, entendido apenas como apêndice de outros projetos para o país.

\section{CONCLUSÃO}

Como em todos os âmbitos do jovem país, o PAIGC interviu na prática esportiva a partir de seus pressupostos, criticando uma certa tradição do esporte que passou a ser encarada como manifestação de um colonialismo que deveria ser extirpado do arquipélago.

O intuito do partido único era mobilizar o esporte na construção do chamado "novo homem cabo-verdiano". Contudo, tal processo encontrou muitas dificuldades

26. Voz di Povo, ano 2, número 85, 19 de fevereiro de 1977, p. 9.

27. Expresso das llhas on line, 21 de setembro de 2007. Disponível em: <http://www.expressodasilhas.cv/noticias/ detail/id/466/> . Acessado em: 24 de maio de 2008. 
e mesmo apresentou certas incoerências. Como coadunar, tanto do ponto de vista ideológico quanto da escassez dos recursos, o desejo de massificação com a necessidade de bons resultados internacionais, algo que interessava tanto aos membros do campo esportivo quanto ao próprio governo, ávido por ver o país reconhecido no cenário mundial e por ver legitimada sua proposta no quadro interno?

A partir de 1977, começa um processo de mudança das propostas do PAIGC, algo que será reforçado em 1980, com a crise na Guiné-Bissau, um golpe de estado que deu fim ao projeto de construção de um Estado único binacional, e culminará com a adoção do multipartidarismo, em 1991.

$\mathrm{Na}$ verdade, os discursos não mudaram diametralmente em 1977, mas três dimensões merecem destaque: a tentativa de efetivamente estruturar ações governamentais; as iniciativas de recuperar os vínculos com São Vicente; a busca de inserção no cenário internacional.

Nesse novo quadro, o esporte participará ainda mais da construção de uma ideia de nação "africana", não mais mestiça. Esse, contudo, é assunto para outra ocasião.

\section{Tensions in a New Country: The Sport in Cape Verde (1974-1977)}

ABSTRACT: This article aims to discuss ideas about the sport published in four Cape Verdian newspaper (Alerta!, Novo Jornal de Cabo Verde, Voz Di Povo e Terra Nova) in the early years of the independent country (1974-1977). We argue that this effort allows us to understand the role played by practice in the first moments of building the idea of nation in Cape Verde, an interesting case in order the late nature of this process and the uniqueness of identity formation in the archipelago. At the end, it is possible to realize that discussions involving the sport, including the nature of government interventions, expressed largely political tensions, social and cultural rights in the country at that time.

KEYWORDS: Sport history; identity; Cape Verde; policy.

\section{En las tensiones de un joven país: el deporte en Cabo Verde (1974- 1977)}

RESUMEN: Este artículo tiene por objetivo discutir las posiciones sobre el deporte vehiculadas en cuatro periódicos de Cabo Verde (Alerta!, Novo Jornal de Cabo Verde, Voz Di Povo e Terra Nova) en los primeros años de la independencia del país (1974-1977). Sostenemos que este esfuerzo nos permite entender el papel desempeñado por la práctica en los primeros momentos de la construcción de la idea de nación en Cabo Verde, un caso interesante en función del carácter tardío de este proceso y de la peculiaridad de la formación de la identidad 
en el archipiélago. Al final, concluyese que los debates alrededor del deporte, en particular con respecto a la naturaleza de las intervenciones del gobierno, expresa en gran medida las tensiones políticas, sociales y culturales en el país en aquello momento.

PALABRAS-CLAVE: Historia del Deporte; identidad; Cabo Verde; política.

\section{REFERÊNCIAS}

ANDERSON, B. Comunidades imaginadas: reflexões sobre a origem e a expansão do nacionalismo. Lisboa: Edições 70, 1991.

FERNANDES, G. Em busca da nação: notas para uma reinterpretação do Cabo Verde crioulo. Florianópolis/Praia: Editora da UFSC/Instituto da Biblioteca Nacional e do Livro, 2006.

HAZAN, B. A. "Sport as an instrument of political expansion: the Soviet Union in Africa". In: BAKER, W. J.; MANGAN, J. A (eds.). Sport in África: essays in social history. Nova lorque: African Publishing Company, 1987. p. 250-27I.

ILIFFE, J. Os africanos: história de um continente. Lisboa: Terramar, 1999.

LOPES, J. V. Cabo Verde: os bastidores da independência. Praia: Spleen Edições, 2002.

MELO, V. A. "Jogando no meio do Atlântico: os primeiros momentos do esporte em Cabo Verde". In: MELO, V. A.; BITTENCOURT, M.; NASCIMENTO, A. (orgs.). Mais do que um jogo: o esporte e o continente africano. Rio de Janeiro: Apicuri, 20 I0. p. I59- 184.

OLIVEIRA, J. N. A imprensa cabo-verdiana: 1820-1975. Macau: Fundação Macau, 1998.

PEREIRA, A. O meu testemunho - uma luta, um partido, dois países. Lisboa: Editorial Notícias, 2003.

QUERIDO, J. Cabo Verde: subsídios para a história da nossa luta de libertação. Lisboa: Veja, 1988.

Recebido em: 19 dez. 2010

Aprovado em: 02 maio 201 I

Endereço para correspondência:

Victor Andrade de Melo

PPGHC/H/UFRJ

Largo de São Francisco, n. I/sala 3 I I

Centro - Rio de Janeiro - RJ

CEP: 2005।-070

victor.a.melo@uol.com.br 